\title{
Different levels of glycosylated hemoglobin influence severity and long-term prognosis of coronary heart disease patients with stent implantation
}

\author{
JING WANG $^{1,2}$, GAOLIANG YAN $^{1}$, YONG QIAO $^{1}$, DONG WANG $^{1}$, GENSHAN MA $^{1}$ and CHENGCHUN TANG ${ }^{1}$ \\ ${ }^{1}$ Department of Cardiology, Zhongda Hospital of Southeast University Medical School, Nanjing, Jiangsu 210009; \\ ${ }^{2}$ Department of Cardiology, Huai'an First People's Hospital, Nanjing Medical University, Huai'an, Jiangsu 223001, P.R. China
}

Received March 21, 2014; Accepted November 11, 2014

DOI: 10.3892/etm.2014.2128

\begin{abstract}
The aim of this study was to investigate the correlation between glycosylated hemoglobin (HbA1c) levels and the severity and long-term prognosis of coronary heart disease (CHD) with stent implantation. A total of 2,825 consecutive patients with stent implantation were stratified into three groups based on the levels of HbAlc: Low HbAlc group (group A, HbA1c $\leq 5.9 \%$ or $41 \mathrm{mmol} / \mathrm{mol}$; $\mathrm{n}=1,035$ ), moderate HbA1c group (group B, $5.9 \%<\mathrm{HbA} 1 \mathrm{c}<6.8 \%$ or $41<\mathrm{HbAlc}<51 \mathrm{mmol} / \mathrm{mol}$; $\mathrm{n}=1,025)$ and high HbA1c group (group C, HbAlc $\geq 6.8 \%$ or $51 \mathrm{mmol} / \mathrm{mol}$; $\mathrm{n}=765$ ). The impact of HbA1c on the Gensini score and the long-term prognosis of $\mathrm{CHD}$ with stent implantation were observed. After an average of 1 year of follow-up of the 2,825 patients in a hospital cohort, participants with low or high HbA1c had a higher risk of major adverse cardiac events (MACE) and target lesion revascularization (TLR) compared with participants with moderate HbAlc after adjusting for multiple potential confounders (hazard ratios for low HbAlc, 1.505 and 1.478, respectively, and for high HbAlc, 1.626 and 1.522, respectively). Analysis of $\mathrm{HbA1c}$ as a continuous variable showed that each $1 \%$ increase of HbA1c was significantly associated with decreased risks of MACE and TLR of 53.5 and 54.2\%, respectively, in those with a low HbA1c level and with increased risks of MACE and TLR of 9.5 and $9.2 \%$, respectively, in those with a moderate or high $\mathrm{HbAlc}$ level, suggesting a U-shaped association between HbAlc and the risk of MACE and TLR. In conclusion, HbA1c levels, either as a continuous variable or a categorical variable, have a U-shaped correlation with MACE and TLR in CHD patients with stent implantation, even after adjustment for multiple confounders.
\end{abstract}

Correspondence to: Dr Chengchun Tang, Department of Cardiology, Zhongda Hospital of Southeast University Medical School, 87 Dingjiaqiao Road, Nanjing, Jiangsu 210009, P.R. China E-mail: tangchengchun@medmail.com.cn

Key words: glycosylated hemoglobin, coronary artery disease, Gensini score, major adverse cardiac events

\section{Introduction}

At present, coronary heart disease (CHD) is a serious concern in China. Diabetes is considered as harmful to health as CHD, and glycosylated hemoglobin A1c (HbA1c) is an important indicator for monitoring blood glucose levels (1-3). HbA1c can indicate the average blood glucose concentration and is highly reproducible and responsive to minor degrees of abnomality in glucose tolerance. Studies have shown that high HbA1c levels can increase the incidence of CHD and adversely affected its prognosis $(4,5)$. Ueda et al found that the levels of HbA1c were significantly higher in patients with major adverse cardiac events compared to those without (4). Fatima et al revealed that $\mathrm{HbA1c}$ is a reliable predictor of coronary artery disease and that the magnitude of perfusion defects, left ventricular dysfunction and the incidence rate of nonfatal myocardial infarction were higher at an HbAlc level $>7.3 \%$ (6). A study by Rocco et al demonstrated that HbAlc was an important predictor of symptomatic hemorrhage following thrombolysis for acute stroke. The results also suggested that hemorrhage following thrombolysis was a consequence of long-term vascular injury rather than of acute hyperglycemia, and that HbAlc may be a more effective predictor than acute blood glucose or a history of diabetes (7). However, the correlation of low HbAlc levels with coronary artery stenosis and prognosis is not yet clear. The present study investigated the correlation between different levels of HbAlc and coronary artery stenosis and evaluated whether $\mathrm{HbA1c}$ is associated with the 1-year risk of major adverse cardiac events (MACE) following successful drug-eluting stent (DES) implantation.

\section{Materials and methods}

Study subjects. A total of 2,825 consecutive patients with CHD who received the first call for drug-eluting coronary stent implantation at the Department of Cardiology, Zhongda Hospital of Southeast University (Nanjing, China) from June 2008 to June 2012 were included in the study. According to $\mathrm{HbA} 1 \mathrm{c}$ levels the patients were divided into three groups. These were the low HbAlc (group A, HbAlc $\leq 5.9 \%$ or $41 \mathrm{mmol} / \mathrm{mol}$; $\mathrm{n}=1,035$ ), medium HbA1c (group B, $5.9 \%<\mathrm{HbA} 1 \mathrm{c}<6.8 \%$ or 
Table I. Baseline clinical characteristics in all 2,825 patients, grouped by baseline HbA1c and by MACE.

\begin{tabular}{|c|c|c|c|c|c|c|c|}
\hline \multirow[b]{2}{*}{ Variable } & \multicolumn{3}{|c|}{ Groups by baseline HbA1c, $\%$} & \multirow[b]{2}{*}{ P-value } & \multicolumn{2}{|c|}{ MACE } & \multirow[b]{2}{*}{ P-value } \\
\hline & $\leq 5.9$ & $5.9-6.8$ & $\geq 6.8$ & & MACE & No-MACE & \\
\hline Age (years) & $59.21 \pm 11.17$ & $59.07 \pm 11.12$ & $61.02 \pm 10.43$ & $<0.001$ & $60.56 \pm 10.59$ & $59.53 \pm 11.04$ & 0.108 \\
\hline Male (\%) & 731 & 456 & 317 & 0.003 & 1689 & 221 & 0.266 \\
\hline Smoking (\%) & 493 & 456 & 317 & 0.038 & 1106 & 160 & 0.138 \\
\hline Hypertension (\%) & 596 & 630 & 526 & $<0.001$ & 1535 & 217 & 0.129 \\
\hline Pulse (bpm) & 70.3 & 70.9 & 73.19 & $<0.001$ & 71.52 & 71.30 & 0.752 \\
\hline Hemoglobin (g/l) & 137.45 & 137.27 & 135.56 & 0.029 & 136.50 & 136.93 & 0.652 \\
\hline Hemoglobin A1c, \% & 4.49 & 5.39 & 7.69 & $<0.001$ & 5.79 & 5.78 & 0.966 \\
\hline Family history of CHD (\%) & 11 & 20 & 16 & 0.174 & 44 & 3 & 0.156 \\
\hline Arrhythmia (\%) & 178 & 156 & 114 & 0.335 & 401 & 47 & 0.176 \\
\hline Hyperlipidemia (\%) & 380 & 427 & 342 & 0.001 & 995 & 154 & 0.025 \\
\hline Diabetes (\%) & 77 & 120 & 384 & $<0.001$ & 496 & 85 & 0.013 \\
\hline Chronic kidney disease (\%) & 617 & 595 & 453 & 0.809 & 1472 & 193 & 0.241 \\
\hline Cerebrovascular disease $(\%)$ & 93 & 72 & 64 & 0.234 & 201 & 28 & 0.453 \\
\hline Body mass index $\left(\mathrm{kg} / \mathrm{m}^{2}\right)$ & 20.0 & 23.4 & 24.5 & 0.376 & 24.3 & 23.2 & 0.144 \\
\hline History of heart failure (\%) & 8 & 24 & 41 & $<0.001$ & 65 & 8 & 0.487 \\
\hline Dual antiplatelet time (days) & 197.1 & 196.8 & 197.8 & 0.920 & 199.01 & 196.94 & 0.488 \\
\hline
\end{tabular}

CHD, coronary heart disease; HbA1c, glycosylated hemoglobin; MACE, major adverse cardiac events.

$41<\mathrm{HbAlc}<51 \mathrm{mmol} / \mathrm{mol} ; \mathrm{n}=1,025)$ and high HbA1c groups (group C, HbAlc $\geq 6.8 \%$ or $51 \mathrm{mmol} / \mathrm{mol} ; \mathrm{n}=765$ ). Exclusion criteria: i) Had received prior percutaneous coronary intervention or coronary artery bypass surgery; ii) simultaneously implanted bare-metal stents and drug-eluting stents; iii) acute coronary syndrome (ACS); iv) severe anemia and other blood system disease, severe infection, trauma, malignancy, severe liver and kidney dysfunction. Ethical approval was obtained from the Ethics Committee of the Faculty of Medicine, Southeast University (Nanjing, China); all patients provided written informed consent prior to participation in the current study. The study complied with the Declaration of Helsinki.

Procedure. Criteria for coronary stenting and coronary artery stenosis were assessed. All patients underwent coronary angiography, and the angiography results were judged by one or two experienced specialist physicians. Any main branch with coronary artery stenosis $\geq 70 \%$ underwent coronary stent implantation. The Gensini scoring system was used to quantify the degree of coronary artery stenosis (8): 1 point, $\leq 25 \%$; 2 points, $26-50 \%$; 4 points, $51-75 \%$; 8 points, $76-90 \%$; 16 points; 91-99\%; 32 points, $100 \%$. This stenosis score multiplied by the appropriate factor for the coronary segment provided the branch score. Each patient's Gensini score was the sum of the scores for every branch.

Clinical follow up. Follow-up via phone, outpatient and/or readmission, and the 1-year MACE rate were recorded during hospitalization and discharge. MACE includes all-cause mortality, non-fatal myocardial infarction (MI) and target lesion revascularization (TLR, involving thrombolysis, stents or bypass).
Statistical analysis. Values are expressed as means \pm standard deviation. Categorical variables were compared using the Chi square test. Differences in the mean values between two groups were compared using an unpaired t-test or a Wilcoxon rank-sum test. The Kaplan-Meier technique was used to plot cumulative event-free estimates. The Cox proportional hazards model was used to analyze the cumulative survival rate among the groups; differences between groups were assessed with the log-rank test. The Backwald method was used to determine the independent risk factors that will influence clinical outcomes. $\mathrm{P}<0.05$ was considered to indicate a statistically significant result. Statistical analyses were performed using the SPSS software package, version 19.0 (IBM, Armonk, NY, USA).

\section{Results}

Baseline characteristics. The baseline characteristics are shown in Table I for all 2,825 patients with stent implantation according to the baseline HbA1c level (group A: $\leq 5.9 \%$, group B: $5.9 \%<\mathrm{HbA1c}<6.8 \%$; group $\mathrm{C}: \geq 6.8 \%$ ) and by MACE follow up (MACE or no-MACE). The mean duration of follow-up was $327 \pm 86.2$ days. Family history of CHD, arrhythmia history, chronic kidney disease, cerebrovascular disease, obesity and dual anti-platelet time were similar for the three HbA1c groups. Age, male gender, smoking, hypertension, pulse rate, hemoglobin level, HbA1c level, hyperlipidemia, diabetes and history of heart failure differed among the three HbAlc groups. Hyperlipidemia and diabetes were different between the two MACE groups, whereas the other baseline characteristics were similar between the two MACE groups. 
Table II. Baseline angiographic characteristics according to baseline HbA1c group and MACE after follow-up.

\begin{tabular}{|c|c|c|c|c|c|c|c|}
\hline \multirow[b]{2}{*}{ Variable } & \multicolumn{3}{|c|}{ Groups by baseline HbA1c, \% } & \multirow[b]{2}{*}{ P-value } & \multicolumn{2}{|c|}{ MACE } & \multirow[b]{2}{*}{ P-value } \\
\hline & $\leq 5.9$ & $5.9-6.8$ & $\geq 6.8$ & & MACE & No-MACE & \\
\hline Gensini score & $29.09 \pm 34.48$ & $28.70 \pm 33.69$ & $37.77 \pm 38.95$ & $<0.001$ & $40.87 \pm 41.49$ & $30.01 \pm 34.66$ & $<0.001$ \\
\hline Number of lesions & 1.40 & 1.45 & 1.70 & $<0.001$ & 1.77 & 1.46 & $<0.001$ \\
\hline Number of stents & 1.94 & 1.25 & 1.87 & 0.394 & 1.73 & 1.94 & 0.020 \\
\hline Number of target vessels & 1.56 & 1.54 & 1.53 & 0.776 & 1.44 & 1.56 & 0.005 \\
\hline Multi-vessel disease & 240 & 228 & 238 & $<0.001$ & 583 & 123 & $<0.001$ \\
\hline Multi-stent & 581 & 573 & 414 & 0.661 & 1401 & 167 & 0.016 \\
\hline Overlapping stents & 298 & 312 & 226 & 0.715 & 752 & 84 & 0.030 \\
\hline Small vessels & 67 & 79 & 53 & 0.544 & 178 & 21 & 0.324 \\
\hline Long lesions & 511 & 485 & 365 & 0.618 & 1213 & 148 & 0.066 \\
\hline Calcification & 93 & 113 & 68 & 0.199 & 248 & 26 & 0.118 \\
\hline СТO & 41 & 47 & 21 & 0.132 & 96 & 13 & 0.537 \\
\hline Bifurcation & 348 & 342 & 251 & 0.936 & 834 & 107 & 0.308 \\
\hline Ostial lesions & 189 & 188 & 160 & 0.290 & 459 & 78 & 0.022 \\
\hline Type C lesions & 401 & 374 & 277 & 0.450 & 2032 & 270 & 0.351 \\
\hline
\end{tabular}

CTO, chronic total occlusion; HbA1c, glycosylated hemoglobin; MACE, major adverse cardiac events.

The baseline angiographic characteristics of the study group are summarized in Table II. Gensini score, number of lesions and incidence of multi-vessel disease differed among the three HbA1c groups. The other baseline angiographic characteristics were similar in the three HbA1c groups. Gensini score, number of lesions, number of stents, number of target vessels, incidence of multi-vessel disease, multi-stent use, overlapping stents and ostial lesions were different between the two MACE groups, whereas the other baseline angiographic characteristics were similar in the two MACE groups.

Survival analysis. As shown in Fig. 1, Kaplan-Meier analysis demonstrated a significantly higher survival rate free from MACE in patients with moderate HbA1c levels $(\mathrm{P}<0.01$, log-rank test). The risk of all-cause mortality of group $\mathrm{C}$ was significantly higher than that of group B. The TLR risks of group $\mathrm{A}$ and group $\mathrm{C}$ were significantly higher than that of group B, while group A and group B, and group B and group C exhibited no significant differences in the risk of MI.

Correlation analysis. Table III shows that a high or low HbA1c level significantly predicted MACE and TLR after adjusting for age, gender, smoking, hypertension, heart rate, hemoglobin, hyperlipidemia, diabetes, heart failure, Gensini score, number of lesions, number of stents, number of target vessels, multivessel disease, multi-stent, overlapping stents and ostial lesions (high HbA1c level, hazard ratio 1.626 and 1.522, respectively; low HbA1c level, hazard ratio 1.505 and 1.478, respectively). A high HbA1c level significantly predicted all cause mortality after adjusting for age, gender, smoking, hypertension, heart rate, hemoglobin, hyperlipidemia, diabetes, heart failure, Gensini score, number of lesions, number of stents, number of target vessels, multi-vessel disease, multi-stent, overlapping stents and ostial lesions (hazard ratio 2.008). Both low and high HbA1c levels are indicated to be risk factors of all-cause mortality, MI and TLR; however, the results are not statistically significant. Analysis of HbAlc as a continuous variable showed that each $1 \%$ increase of $\mathrm{HbA1c}$ was significantly associated with a decreased risk of MACE and TLR by 53.5 and $54.2 \%$, respectively, in those with a low HbAlc level, and with an increased risk of MACE and TLR by 10 and $9.2 \%$, respectively, in those with a moderate or high HbAlc level, suggesting a U-shaped association between HbAlc and the risk of MACE and TLR, even after adjusting for baseline potential confounders.

\section{Discussion}

In this study of 2,825 older patients with CHD in a hospital cohort followed up for an average of 1 years, an approximately U-shaped association between HbAlc and MACE and TLR was found. Patients with low ( $\leq 41 \mathrm{mmol} / \mathrm{mol}$ or $5.9 \%$ ) or high ( $\geq 51 \mathrm{mmol} / \mathrm{mol}$ or $6.8 \%$ ) HbAlc levels had a risk of MACE or TLR that was higher than that of participants with moderate (41-51 $\mathrm{mmol} / \mathrm{mol}$ or 5.9-6.8\%) HbA1c levels after adjusting for multiple potential confounders (hazard ratios for low HbAlc, 1.505 and 1.478, respectively, and for high HbAlc, 1.626, 1.522 , respectively). Analysis of HbA1c as a continuous variable showed that each $1 \%$ increase of HbA1c was significantly associated with decreased risks of MACE and TLR of 53.5 and $54.2 \%$, respectively, in patients with a low level of HbAlc and with increased risks of MACE and TLR of 9.5 and $9.2 \%$, respectively, in those with a moderate or high HbAlc level, suggesting a U-shaped association between HbA1c and the risk of MACE and TLR.

A number of studies have focused on the use of HbA1c levels for the prognosis of patients with diabetes $(6,7,9)$. A meta-analysis of four randomized clinical trials (10), Action to Control Cardiovascular Risk in Diabetes (ACCORD) (11), 

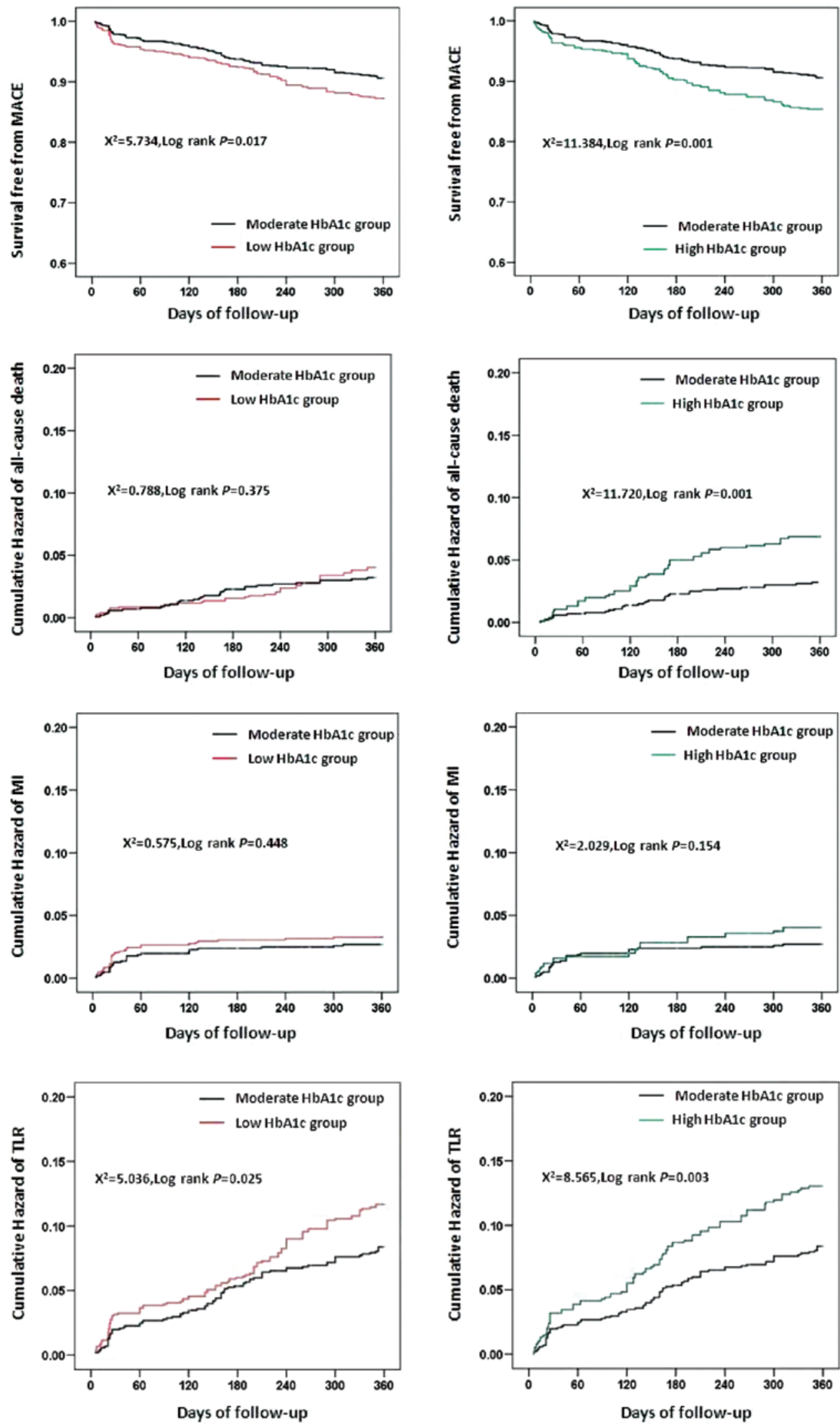

Figure 1. Kaplan-Meier curves representing survival rate free from MACE, and cumulative hazard of all cause mortality, MI and TLR in the three groups. MACE, major adverse cardiac events; Hb1 Ac, glycosylated hemoglobin; MI, myocardial infarction; TLR, target lesion revascularization.

Action in Diabetes and Vascular Disease: Preterax and Diamicron Modified Release Controlled Evaluation (ADVANCE) (12), the UK Prospective Diabetes Study (13) and Veterans Affairs Diabetes Trial (14), found that all-cause and cardiovascular mortality did not increase in the intensive glycemic control group (target glycated hemoglobin $\leq 6.5 \%$, 
Table III. Adjusted hazard ratios of MACE, all-cause mortality, MI and TLR in 2,825 patients with CHD following PCI by continuous and grouped HbA1c levels (mean follow-up, 1 year).

\begin{tabular}{|c|c|c|c|c|c|}
\hline \multirow[b]{2}{*}{ Variable } & \multicolumn{2}{|c|}{ HbA1c continuous ${ }^{\mathrm{a}}, \%$} & \multicolumn{3}{|c|}{ HbA1c groups, $\%$} \\
\hline & $\leq 5.9^{\mathrm{b}}$ & $>5.9^{c}$ & $\leq 5.9$ & $5.9-6.8$ & $\geq 6.8$ \\
\hline \multicolumn{6}{|l|}{ MACE } \\
\hline Crude hazard ratio & $0.435(<0.001)^{\mathrm{d}}$ & $1.100(0.004)^{\mathrm{e}}$ & $1.379(0.017)^{\mathrm{f}}$ & Ref & $1.101(0.084)$ \\
\hline Model 1 & $0.474(0.098)$ & $1.004(0.956)$ & $1.483(0.005)^{\mathrm{f}}$ & Ref & $1.712(<0.001)^{\mathrm{c}}$ \\
\hline Model 2 & $0.465(0.002)^{\mathrm{e}}$ & $1.095(0.01)^{\mathrm{e}}$ & $1.505(0.004)^{\mathrm{f}}$ & Ref & $1.626(0.001)^{\mathrm{b}}$ \\
\hline \multicolumn{6}{|l|}{ Mortality } \\
\hline Crude hazard ratio & $0.324(0.115)$ & $1.172(0.034)^{\mathrm{f}}$ & $1.234(0.376)$ & Ref & $1.172(0.034)^{\mathrm{a}}$ \\
\hline Model 1 & $0.780(0.104)$ & $0.985(0.892)$ & $1.246(0.380)$ & Ref & $2.092(0.002)^{\mathrm{b}}$ \\
\hline Model 2 & $0.535(0.158)$ & $1.049(0.466)$ & $1.264(0.354)$ & Ref & $2.008(0.004)^{\mathrm{b}}$ \\
\hline \multicolumn{6}{|l|}{ MI } \\
\hline Crude hazard ratio & $0.128(0.005)^{\mathrm{e}}$ & $1.002(0.989)$ & $1.217(0.449)$ & Ref & $1.002(0.989)$ \\
\hline Model 1 & $0.663(0.033)^{\mathrm{f}}$ & $1.003(0.985)$ & $1.359(0.262)$ & Ref & $1.712(0.056)$ \\
\hline Model 2 & $0.6(0.295)$ & $1.116(0.068)$ & $1.418(0.202)$ & Ref & $1.582(0.106)$ \\
\hline \multicolumn{6}{|l|}{ TLR } \\
\hline Crude hazard ratio & $0.228(<0.001)^{\mathrm{d}}$ & $1.127(0.042)^{\mathrm{f}}$ & $1.385(0.026)^{\mathrm{f}}$ & Ref & $1.127(0.042)^{\mathrm{a}}$ \\
\hline Model 1 & $0.577(0.110)$ & $1.194(0.864)$ & $1.460(0.013)^{\mathrm{f}}$ & Ref & $1.595(0.004)^{\mathrm{b}}$ \\
\hline Model 2 & $0.458(0.003)^{\mathrm{e}}$ & $1.092(0.021)^{\mathrm{f}}$ & $1.478(0.01)^{\mathrm{e}}$ & Ref & $1.522(0.009)^{\mathrm{b}}$ \\
\hline $\begin{array}{l}\text { Ref, reference, with the } \\
\text { heart failure. Model } 2 \\
\text { ease, multi-stent, overla } \\
4.2 \text { to } 5.9 \text { in the analysi } \\
\text { disease and stroke mort }\end{array}$ & $\begin{array}{l}\text { rate. Model } 1 \text { adju } \\
\text { lly adjusted for Ge } \\
\text { tents and ostial lesi } \\
\text { iovascular disease } \\
<0.001,{ }^{\mathrm{e}} \mathrm{P}<0.01 \text { an }\end{array}$ & $\begin{array}{l}\text { r age, sex, smoki } \\
\text { core, number of } \\
\text { lazard ratios for } \mathrm{F} \\
\text { oke mortality; }{ }^{\mathrm{C}} \mathrm{H} \\
.05 \text {. }\end{array}$ & $\begin{array}{l}\text { ertension, heart ra } \\
\text { number of stents, } \\
\text { continuous were pe } \\
\text { evel ranged from } 5\end{array}$ & $\begin{array}{l}\text { oglobin, } h \\
\text { of target } \\
\text { crease; }{ }^{b} \mathrm{H} \\
.5 \text { in the ar }\end{array}$ & $\begin{array}{l}\text { ipidemia, diabetes, } \\
\text { l, multi-vessel dis- } \\
\text { level ranged from } \\
\text { s of cardiovascular }\end{array}$ \\
\hline
\end{tabular}

fasting blood glucose $<6.0 \mathrm{mmol} / \mathrm{l}$ or absolute $\mathrm{HbA} 1 \mathrm{c}$ reduction $1.5 \%$ ) compared with a non-intensive control group, with a median follow-up period from 3.4-5.6 years. The External Peer Review Program (EPRP) study of a cohort of 5,815 heart failure patients without diabetes found a U-shaped association between HbA1c and all-cause mortality (15). Xu et al found that higher and lower HbA1c levels increased the risk of mortality compared with that for moderate glycemic control (7.1-7.8\%), even after adjustment for potential baseline confounders. In comparison with patients with HbAlc levels of 7.5-8.4\%, those with lower $(<48 \mathrm{mmol} / \mathrm{mol}, 6.5 \%)$ or higher $(>69 \mathrm{mmol} / \mathrm{mol}$, $8.5 \%) \mathrm{HbA} 1 \mathrm{c}$ levels had increased stroke mortality risks of $112 \%$ and $143 \%$, respectively (16).

However, the relationship between HbA1c and CHD prognosis remains controversial. Ciciek et al (17) found that $\mathrm{HbAlc}$ is an independent predictor of the in-hospital mortality of ST elevation MI (STEMI) patients treated with PCI. Corpus et al (18) demonstrated that HbAlc is a significant predictor of MACE, target vessel revascularization (TVR) and cardiac death 1 year following PCI in non-diabetic patients. Hadjadj et al (19) found that HbA1c was not associated with STEMI prognosis in a small population. Lemesle et al (20). demonstrated that HbA1c is not a predictor for cardiac events in diabetic patients with coronary artery disease. The data in the present study show that, compared with patients with moderate HbAlc levels (range, 5.9-6.8\%), those with higher
HbA1c levels had higher risks of MACE and TLR of 62.6 and $52.2 \%$, respectively. The conflicting relationship between HbAlc levels and prognosis may have several interpretations. One reason may be due to different definitions and follow-up times of the end point. Another reason may be differences in the study. Corpus, et al (18) defined the primary endpoint as TVR, secondary endpoint as cardiac death, MI, recurrent angina, stroke, congestive heart failure, renal failure and cardiac rehospitalization, and the study was of non-diabetic patients with CHD. Lemesle et al (20) defined the primary endpoint as mortality, MI and TVR, used a 1-year follow-up, 70\% of patients received stents and studied CHD patients with DM. In the present study, the endpoint is defined as mortality, non-fatal MI and TLR through PCI, and the subjects were CHD patients with or without DM; all patients received stent implantation. HbA1c and a composite endpoint (cardiovascular death, nonfatal MI or TLR) to assess whether the definition of the end result affected the correlation between HbAlc and the endpoint. Cardiovascular death and TLR were found to be significantly correlated with HbAlc.

There have been relatively few studies concerning the correlation between low HbAlc level and the prognosis of CHD patients. The present study suggests that compared with patients with moderate HbAlc levels (range, 5.9-6.8\%), those with lower $\mathrm{HbA1c}$ levels had increased risks of MACE and TLR of 50.5 and $47.8 \%$, respectively. The results are consistent with a U-shaped 
correlation between $\mathrm{HbAlc}$ and the prognosis of diabetic patients. Intensive glucose control, resulting in low levels of HbAlc and severe hypoglycemia, may lead to subsequent higher mortality, which may explain the results of this study.

The present study has several limitations. First, antidiabetic drugs may have affected the results. This study was not designed to test the results of the treatment of diabetes; due to lack of data, it was not possible to study the therapeutic effect of such treatment. Secondly, the HbA1c level measurements were not repeated, and in subsequent years, HbA1c levels may have changed. Thirdly, the observed increases in MACE and TLR were independent of sex, gender, hypertension, hyperlipidemia and history of heart failure. Nonetheless, it is not possible to exclude residual confounding by other known and unknown risk factors, such as fasting blood glucose or inflammatory markers, which were not covered in the analysis. Fourthly, due to telephone interviews and the cause of mortality being reported by a family member or loved one, misjudgment of the cause of mortality cannot be completely ruled out. Finally, the severity of cardiovascular disease at baseline cannot be assessed based on the self-reported history. Therefore, misjudgment of cardiovascular disease cannot be eliminated.

In summary, this study found that HbAlc levels, either as a continuous variable or a categorical variable, have a U-shaped correlation with MACE and TLR in CHD patients with stent implantation, even following adjustment for multiple confounders. Based on the aforementioned limitations of this study, more rigorous and comprehensive studies are required to confirm these findings.

\section{References}

1. Baber U, Gutierrez OM, Levitan EB, Warnock DG, Farkouh ME, et al: Risk for recurrent coronary heart disease and all-cause mortality among individuals with chronic kidney disease compared with diabetes mellitus, metabolic syndrome, and cigarette smokers. Am Heart J 166: 373-380, 2013.

2. Kim J, Chae YK and Chernoff A: The risk for coronary heart disease according to insulin resistance with and without type 2 diabetes. Endocr Res 38: 195-205, 2013.

3. Saely $\mathrm{CH}$ and Drexel $\mathrm{H}$ : Is type 2 diabetes really a coronary heart disease risk equivalent? Vascul Pharmacol 59: 11-18, 2013.

4. Ueda H, Mitsusada N, Harimoto K, Miyawaki M, Yasuga Y and Hiraoka H: Glycosylated hemoglobin is a predictor of major adverse cardiac events after drug-eluting stent implantation in patients with diabetes mellitus. Cardiology 116: 51-57, 2010.

5. Kataoka Y, Shao M, et al: Multiple risk factor intervention and progression of coronary atherosclerosis in patients with type 2 diabetes mellitus. Eur J Prev Cardiol 20: 209-217, 2013.
6. Gensini GG: A more meaningful scoring system for determining the severity of coronary heart disease. Am J Cardiol 51: 606, 1983.

7. Fatima N, u Zaman M, Ishaq M, Baloch DJ, Bano M, et al: Impact of glycosylated hemoglobin (HBA1C) on the extent of perfusion abnormalities and left ventricular dysfunction using gated myocardial perfusion imaging and clinical outcomes in diabetic patients. Nucl Med Commun 34: 489-494, 2013.

8. Rocco A, Heuschmann PU, Schellinger PD, Köhrmann M, Diedler J, et al: Glycosylated hemoglobin A1 predicts risk for symptomatic hemorrhage after thrombolysis for acute stroke. Stroke 44: 2134-2138, 2013.

9. Su G, Mi SH, Tao H, Li Z, Yang HX, et al: Impact of admission glycemic variability, glucose, and glycosylated hemoglobin on major adverse cardiac events after acute myocardial infarction. Diabetes Care 36: 1026-1032, 2013.

10. Control Group; Turnbull FM, Abraira C, Anderson RJ, Byington RP, Chalmers JP, et al: Intensive glucose control and macrovascular outcomes in type 2 diabetes. Diabetologia 52: 2288-2298, 2009.

11. Action to Control Cardiovascular Risk in Diabetes Study Group; Gerstein HC, Miller ME, Byington RP, Goff DC Jr, Bigger JT, et al: Effects of intensive glucose lowering in type 2 diabetes. N Engl J Med 358: 2545-2559, 2008

12. Zoungas S, Chalmers J, Ninomiya T, Li Q, Cooper ME, et al; ADVANCE Collaborative Group: Association of HbA1c levels with vascular complications and death in patients with type 2 diabetes: evidence of glycaemic thresholds. Diabetologia 55: 636-643, 2012.

13. Holman RR, Paul SK, Bethel MA, Matthews DR and Neil HA: 10-year follow-up of intensive glucose control in type 2 diabetes. N Engl J Med 359: 1577-1589, 2008.

14. Agrawal L, Emanuele NV, Abraira C, Henderson WG, Levin SR, et al: Ethnic differences in the glycemic response to exogenous insulin treatment in the Veterans Affairs Cooperative Study in Type 2 Diabetes Mellitus (VA CSDM). Diabetes Care 21: 510-515, 1998.

15. Aguilar D, Bozkurt B, Ramasubbu K and Deswal A: Relationship of hemoglobin A1C and mortality in heart failure patients with diabetes. J Am Coll Cardiol 54: 422-428, 2009.

16. Xu L, Chan WM, Hui YF and Lam TH: Association between HbAlc and cardiovascular disease mortality in older Hong Kong Chinese with diabetes. Diabet Med 29: 393-398, 2012.

17. Cicek G, Uyarel H, Ergelen M, Ayhan E, Abanonu GB, et al: Hemoglobin A1c as a prognostic marker in patients undergoing primary angioplasty for acute myocardial infarction. Coronary Artery Disease 22: 131-137, 2011.

18. Corpus RA, O'Neill WW, Dixon SR, Timmis GC and Devlin WH: Relation of hemoglobin A1c to rate of major adverse cardiac events in nondiabetic patients undergoing percutaneous coronary revascularization. Am J Cardiol 92: 1282-1286, 2003.

19. Hadjadj S, Coisne D, Mauco G, Ragot S, Duengler F, et al: Prognostic value of admission plasma glucose and $\mathrm{HbA}$ in acute myocardial infarction. Diabet Med 21: 305-310, 2004.

20. Lemesle G, Bonello L, de Labriolle A, Maluenda G, Syed AI, et al: Prognostic value of hemoglobin A1C levels in patients with diabetes mellitus undergoing percutaneous coronary intervention with stent implantation. Am J Cardiol 104: 41-45, 2009. 